\title{
CARACTERÍSTICAS ANALÍTICAS DOS SUCOS DE MAÇÃ GALA, GOLDEN DELICIOUS E FUJI ${ }^{1}$
}

\author{
Luiz Antenor RIZZON ${ }^{2, *}$, João BERNARDI ${ }^{2}$, Alberto MIELE ${ }^{2}$
}

\section{RESUMO}

Dentre as frutas de clima temperado cultivadas no Brasil, a maçã apresentou maior expansão de produção nos últimos anos. Ela se destina principalmente ao consumo in natura, mas o suco se constitui em subproduto a ser considerado. Portanto, a elaboração de suco de maçã é uma alternativa para aproveitar as frutas consideradas como descarte. Com o objetivo de aproveitar o descarte das maçãs Gala, Golden Delicious e Fuji, foi estudada a composição de seus sucos. Nas safras de 1995 a 1997 foram analisados os sucos dessas cultivares de maçã colhidas de pomares comerciais dos municípios de Fraiburgo e São Joaquim - SC e de Vacaria e Caxias do Sul - RS. Além das análises básicas dos sucos, realizadas por métodos físico-químicos, foram determinados também os elementos minerais por absorção atômica. Os resultados foram submetidos à análise de componentes principais (ACP), sendo que os três primeiros eixos explicaram $81,3 \%$ da variação total. Através da ACP, foi possível separar os sucos das três cultivares de maçã. As variáveis que apresentaram maior efeito na diferenciação do suco de maçã foram sólidos solúveis totais ( $\left.{ }^{\circ} B r i x\right)$, densidade (DEN), açúcares redutores (AR), relação ${ }^{\circ} \mathrm{Brix} / \mathrm{acidez}$ total (B/A), acidez total (ACT), ácido málico (ACM) e os minerais Mg, Cu, Zn, $\mathrm{Rb}, \mathrm{P}$ e K. Quanto à origem geográfica, os sucos de maçã de São Joaquim - SC e de Vacaria - RS mostraram maiores semelhanças em sua composição, principalmente nas cultivares Fuji e Golden Delicious.

Palavras-chave: processamento, suco de maçã, composição química.

\section{SUMMARY}

ANALYTICAL CHARACTERISTICS OF GALA, GOLDEN DELICIOUS AND FUJI APPLE JUICE FROM SOUTH OF BRAZIL. Among temperate fruits cultivated in Brazil, the production of apple increased the most in the last years. It is mainly addressed to the consumption in natura, but juice is becoming an important by-product. For this reason, it is an alternative to utilize rejected fruits to make juice. With the objective to reach this goal, the composition of Gala, Golden Delicious, and Fuji juices was studied. This experiment was conducted from 1995 to 1997, analyzing apple juices from commercial orchards of Fraiburgo and São Joaquim, in the State of Santa Catarina, and Vacaria and Caxias do Sul, in the State of Rio Grande do Sul. Besides the juice analysis, performed by physicochemical methods, mineral composition was determined by atomic absorption. Data were submitted to principal component analysis (PCA) where the three first axes explained $81.3 \%$ of the total variation. The PCA permitted to separate the juices according to cultivars. The variables presenting the highest effect in apple juice differentiation were total soluble solids ( $\left.{ }^{\circ} \mathrm{Brix}\right)$, density (DEN), reducing sugars (AR), ${ }^{\circ} \mathrm{Brix} / \mathrm{Total}$ acidity (ACT) ratio, malic acid (ACM), and the minerals $\mathrm{Mg}, \mathrm{Cu}, \mathrm{Zn}, \mathrm{Rb}, \mathrm{P}$ and $\mathrm{K}$. Regarding the geographical origin, juices from São Joaquim - SC and Vacaria - RS showed more similarities in their composition, mainly due to Fuji and Golden Delicious cultivars.

Keywords: processing, apple juice, chemical composition.

\section{1 - INTRODUÇÃO}

A maçã é, dentre as frutas de clima temperado cultivadas no Brasil, aquela que apresentou maior expansão em área plantada e em volume de produção nos últimos vinte anos. De um total de 931 ha em 1972, a área plantada passou para 18.041 ha em 1980 [5]. Em 2002 já havia mais de 32.500 ha ocupados com macieiras, o que mostra um incremento médio de aproximadamente 500 ha/ano [20].

O cultivo da maçã no país se concentra na Região Sul. Santa Catarina é o maior produtor, com aproximadamente $51 \%$ do total da área plantada. Fraiburgo é o município maior produtor de maçãs do país, seguido de São Joaquim e Lebon Régis. Localizado a 1400 m de altitude, no Planalto Catarinense, São Joaquim apresenta condições climáticas adequadas ao cultivo de macieiras, pois permite naturalmente a ocorrência da quebra de dormência das gemas [22].

${ }^{1}$ Recebido para publicação em 04/01/2005. Aceito para publicação em 18/10/2005 (001459).

${ }^{2}$ Embrapa Uva e Vinho, Caixa Postal 130, CEP 95700-000 - Bento Gonçalves, RS. Fone: (54)455-8000.E-mails: rizzon@cnpuv.embrapa.br; bernardi@ cnpuv.embrapa.br; miele@cnpuv.embrapa.br.

*A quem a correspondência deve ser enviada.
O Rio Grande do Sul é o segundo Estado produtor, com aproximadamente $40 \%$ do total da área plantada. Vacaria, com uma área de 5.575 ha, é o município maior produtor. Mas, o cultivo da maçã também é expressivo nos municípios de Bom Jesus, São Francisco de Paula, Cambará do Sul, Antônio Prado, Caxias do Sul, Ipê e Lagoa Vermelha. MOTA \& ALVES [14] e WESTPHALEN \& MALUF [25] classificaram a região de Vacaria como preferencial para o cultivo da maçã, levando em consideração o número de horas de frio/ano (500 a 600) com temperatura abaixo de $7,2^{\circ} \mathrm{C}$, acumuladas de maio a agosto.

O plantio da maçã no Brasil teve como primeiro objetivo suprir o mercado interno para consumo in natura. No entanto, hoje apresenta perspectiva favorável também para sua exportação e para a produção e exportação de suco concentrado. Além do suco, a maçã pode ser aproveitada na elaboração de sidra, vinagre, destilado e extração de pectina [1, 23].

O suco e os demais derivados da maçã são elaborados principalmente a partir de frutas consideradas como descarte, que não alcançam o padrão exigido para consumo (aspecto, tamanho, uniformidade e outros defeitos) e de cultivares que não apresentam aptidão específica. Em algumas regiões do mundo estão sendo feitos estudos para 
a implantação de pomares de macieiras especialmente orientados para a produção de maçãs para suco, utilizando cultivares com maior acidez, resistentes à sarna e com custo de produção mais baixo [13, 26]. As melhores maçãs para a elaboração de suco são aquelas que possuem teores elevados de açúcares e de ácidos. Assim, os frutos pequenos das cultivares de maçãs para consumo in natura podem originar bons sucos.

No Brasil, o volume de maçã utilizado pela agroindústria ainda não chega a $15 \%$, enquanto na Argentina a industrialização beneficia em torno de $30 \%$ da produção. Em relação às cultivares, mais de $95 \%$ dos pomares brasileiros são formados principalmente pelas cultivares Gala e suas mutações Royal Gala, Imperial Gala, Mondial Gala - e Fuji - dentre elas, Fuji Suprema e Kiko -, vindo em seguida a Golden Delicious, sendo todas indicadas para a elaboração de suco [17].

A estrutura agroindustrial existente em Santa Catarina e no Rio Grande do Sul está adaptada para a transformação da crescente disponibilidade de maçã. Quanto ao rendimento, em média são necessários 8 kg de maçã para produzir $1 \mathrm{~kg}$ de suco concentrado com aproximadamente $68^{\circ}$ Brix e densidade de $1,350 \mathrm{mg} \mathrm{mL}-1$ a $20^{\circ} \mathrm{C}$. Entretanto, até o momento, não foram estabelecidos os padrões analíticos para os sucos de maçã elaborados no Brasil, pois é um produto relativamente novo e com pouca tradição no mercado internacional. Mas, na Alemanha, a normatização do suco de maçã é feita pelo Controle Federal de Alimentos, com valores analíticos previamente estabelecidos, de modo que todo suco importado de outros países deve se enquadrar nesses limites [24]. Os países importadores de suco de maçã valorizam muito a autenticidade da origem geográfica [4, 11, 12, 13].

De modo geral, a composição do suco de maçã é conseqüência dos fatores naturais onde estão instalados os pomares (solo, clima), dos fatores agronômicos de produção da fruta (cultivares, tratos culturais, adubações, tratamentos fitossanitários, épocas de colheita) e da tecnologia de elaboração [9]. Assim, ao longo do tempo, vários trabalhos têm sido desenvolvidos em função desses fatores, considerando diferentes grupos de compostos como os açúcares [10], os ácidos orgânicos [3], as substâncias aromáticas [9] e, principalmente, os compostos fenólicos [8, 19].

O objetivo do presente trabalho foi determinar a composição físico-química do suco das maçãs Gala, Golden Delicious e Fuji, cultivadas nos Estados de Santa Catarina e do Rio Grande do Sul, visando à sua caracterização.

\section{2 - MATERIAL E MÉTODOS}

Foram efetuadas análises dos sucos das maçãs Gala, Golden Delicious e Fuji nas safras de 1995 a 1997, provenientes de pomares dos municípios de Fraiburgo e São Joaquim - SC e de Vacaria e Caxias do Sul - RS. Em cada localidade foram selecionados três pomares com as cultivares estudadas, representativos em relação à idade das plantas, ao porta-enxerto, ao tipo de solo, à exposição, à adubação e aos tratos culturais. Foram colhidos aproximadamente $5 \mathrm{~kg}$ de maçã madura, calibre 175 , de cada cultivar e em cada safra. O suco foi obtido pela trituração das maçãs, previamente lavadas com água e a seguir, o suco foi centrifugado e analisado nos Laboratórios de Enoquímica e Instrumentação da Embrapa Uva e Vinho, em Bento Gonçalves - RS.

A densidade foi determinada com um densímetro digital Anton Paar; a acidez total foi analisada por titulação com solução alcalina de uma alíquota do mosto de maçã; o pH foi medido com potenciômetro calibrado com soluçõestampão de pH 3,0 e pH 4,0; os açúcares redutores totais foram analisados pela reação com solução cupro-alcalina; $\mathrm{O}{ }^{\circ}$ Brix foi determinado com um refratômetro Abbe a $20^{\circ} \mathrm{C}$; as cinzas foram obtidas pela incineração da amostra, num cadinho de platina, a $550^{\circ} \mathrm{C}$ e pesadas [15]; a prolina foi determinada pelo método colorimétrico, com a ninidrina, no qual a cor vermelha desenvolvida em meio ácido e a quente foi medida a $517 \mathrm{~nm}$ [7].

Dentre os elementos minerais, o P foi analisado pelo método colorimétrico com solução sulfomolíbdica. A análise dos cátions foi feita por espectrofotometria, sendo que o $\mathrm{K}, \mathrm{Na}$, Li e $\mathrm{Rb}$ foram avaliados por emissão de chama, sendo que o $\mathrm{Ca}, \mathrm{Mg}, \mathrm{Mn}, \mathrm{Fe}, \mathrm{Cu}$ e $\mathrm{Zn}$ por absorção atômica [16].

O ácido málico foi analisado por cromatografia líquida de alta eficiência (CLAE), utilizando-se um cromatógrafo líquido Varian, operando em condição isocrática, com detector espectrofotométrico UV/VIS, modelo UV-50 e um injetor Rheodyne 7125 , de $20 \mu \mathrm{L}$. A separação do ácido málico foi realizada em uma coluna MCH-NCAP-5 de $15 \mathrm{~cm}$ de comprimento $\mathrm{x}$ 4,6 mm de diâmetro interno. O detector foi fixado no comprimento de onda de $212 \mathrm{~nm}$. Na eluição, utilizou-se como solvente água ultrapura acidificada com ácido fosfórico, a pH 2,5 [2].

O estudo das diferenças dos sucos de maçã foi feito através da utilização da análise de componentes principais (ACP), segundo o programa STAT-ITCF. A ACP permite a construção de planos fatoriais onde os eixos são combinações lineares das variáveis iniciais (descritores) e a visualização das relações entre essas variáveis e os produtos (sucos de maçã) [6].

\section{3 - RESULTADOS E DISCUSSÃO}

Os teores médios e os coeficientes de variação das variáveis físico-químicas determinadas nos sucos das maçãs Gala, Golden Delicious e Fuji, das safras de 1995 a 1997, são apresentados na Tabela 1, sendo que os teores dos sucos de maçã de Fraiburgo e São Joaquim - SC e de Vacaria e Caxias do Sul - RS, são apresentados na Tabela 2.

De modo geral, os valores quantitativos obtidos dos sucos de maçã correspondem àqueles encontrados em outras regiões produtoras [13, 24]. No entanto, observaram-se teores mais baixos de $\mathrm{Na}$, $\mathrm{Ca}$ e $\mathrm{Mg}$ nos sucos das maçãs analisadas. Teores baixos de Na foram encontrados também em sucos de frutas brasileiras [21]. Em relação 
TABELA 1 - Média e coeficiente de variação das análises físico-químicas dos sucos das maçãs Gala, Golden Delicious e Fuji, safras 1995,1996 e 1997

\begin{tabular}{|c|c|c|c|c|c|c|}
\hline \multirow{3}{*}{ Variável } & \multicolumn{6}{|c|}{ Cultivar de Maçã } \\
\hline & \multicolumn{2}{|c|}{ Gala } & \multicolumn{2}{|c|}{ Golden Delicious } & \multicolumn{2}{|c|}{ Fuji } \\
\hline & Média & $\mathrm{CV}(\%)$ & Média & $\mathrm{CV}(\%)$ & Média & $\mathrm{CV}(\%)$ \\
\hline Densidade $\left(\mathrm{mg} \mathrm{mL}^{-1}\right)$ a $20^{\circ} \mathrm{C}$ & 1,0517 & 0,30 & 1,0541 & 0,42 & 1,0583 & 0,42 \\
\hline Sólidos solúveis totais ( ${ }^{\circ}$ Brix) & 12,4 & 5,9 & 12,9 & 8,7 & 14,0 & 7,7 \\
\hline Acidez total (meq L-1) & 49,4 & 12,4 & 59,4 & 11,5 & 44,0 & 13,1 \\
\hline Ácido málico $\left(\mathrm{g} \mathrm{L}^{-1}\right)$ & 4,0 & 13,5 & 4,5 & 10,3 & 3,9 & 8,7 \\
\hline Relação Brix/Acidez total & 38,1 & 10,8 & 32,6 & 9,9 & 47,8 & 14,2 \\
\hline $\mathrm{pH}$ & 3,67 & 2,18 & 3,44 & 3,27 & 3,74 & 2,89 \\
\hline Açúcares redutores $\left(\mathrm{g} \mathrm{L}^{-1}\right)$ & 71,8 & 8,2 & 86,2 & 10,7 & 90,1 & 11,9 \\
\hline Açúcares totais $\left(\mathrm{g} \mathrm{L}^{-1}\right)$ & 93,9 & 11,8 & 111,7 & 14,6 & 105,8 & 8,3 \\
\hline Cinzas $\left(\mathrm{g} \mathrm{L}^{-1}\right)$ & 2,76 & 24,6 & 2,11 & 21,1 & 2,44 & 14,16 \\
\hline Prolina $\left(\mathrm{mg} \mathrm{L}^{-1}\right)$ & 14,7 & 51,3 & 9,2 & 54,0 & 9,4 & 31,2 \\
\hline $\mathrm{K}\left(\mathrm{mg} \mathrm{L}^{-1}\right)$ & 1054 & 9,9 & 924 & 17,5 & 1060 & 14,5 \\
\hline $\mathrm{Na}\left(\mathrm{mg} \mathrm{L}^{-1}\right)$ & 2,4 & 49,6 & 1,8 & 47,9 & 2,2 & 39,4 \\
\hline $\mathrm{Ca}\left(\mathrm{mg} \mathrm{L}^{-1}\right)$ & 21,5 & 19,5 & 13,4 & 21,8 & 13,4 & 15,1 \\
\hline $\mathrm{Mg}\left(\mathrm{mg} \mathrm{L}^{-1}\right)$ & 34,8 & 12,8 & 33,5 & 15,0 & 27,3 & 11,1 \\
\hline $\mathrm{Mn}\left(\mathrm{mg} \mathrm{L}^{-1}\right)$ & 0,4 & 28,7 & 0,5 & 31,9 & 0,6 & 117,9 \\
\hline $\mathrm{Cu}\left(\mathrm{mg} \mathrm{L}^{-1}\right)$ & 1,0 & 73,2 & 0,9 & 81,4 & 0,5 & 29,5 \\
\hline $\mathrm{Fe}\left(\mathrm{mg} \mathrm{L}^{-1}\right)$ & 0,42 & 26,7 & 0,40 & 46,5 & 0,42 & 38,7 \\
\hline $\mathrm{Zn}\left(\mathrm{mg} \mathrm{L}^{-1}\right)$ & 0,7 & 116,4 & 0,7 & 122,9 & 0,3 & 74,1 \\
\hline $\mathrm{Li}(\mu \mathrm{g} \mathrm{L}-1)$ & 0,7 & 139,0 & 0,5 & 71,6 & 0,5 & 78,2 \\
\hline $\mathrm{Rb}\left(\mathrm{mg} \mathrm{L}^{-1}\right)$ & 0,9 & 53,9 & 1,3 & 46,2 & 1,7 & 47,9 \\
\hline$P\left(\mathrm{mg} \mathrm{L}^{-1}\right)$ & 62,2 & 21,1 & 44,2 & 32,9 & 69,8 & 21,7 \\
\hline
\end{tabular}

TABELA 2 - Média e coeficiente de variação das análises físico-químicas dos sucos das maçãs de Fraiburgo e São Joaquim - SC e de Vacaria e Caxias do Sul - RS, safras 1995, 1996 e 1997

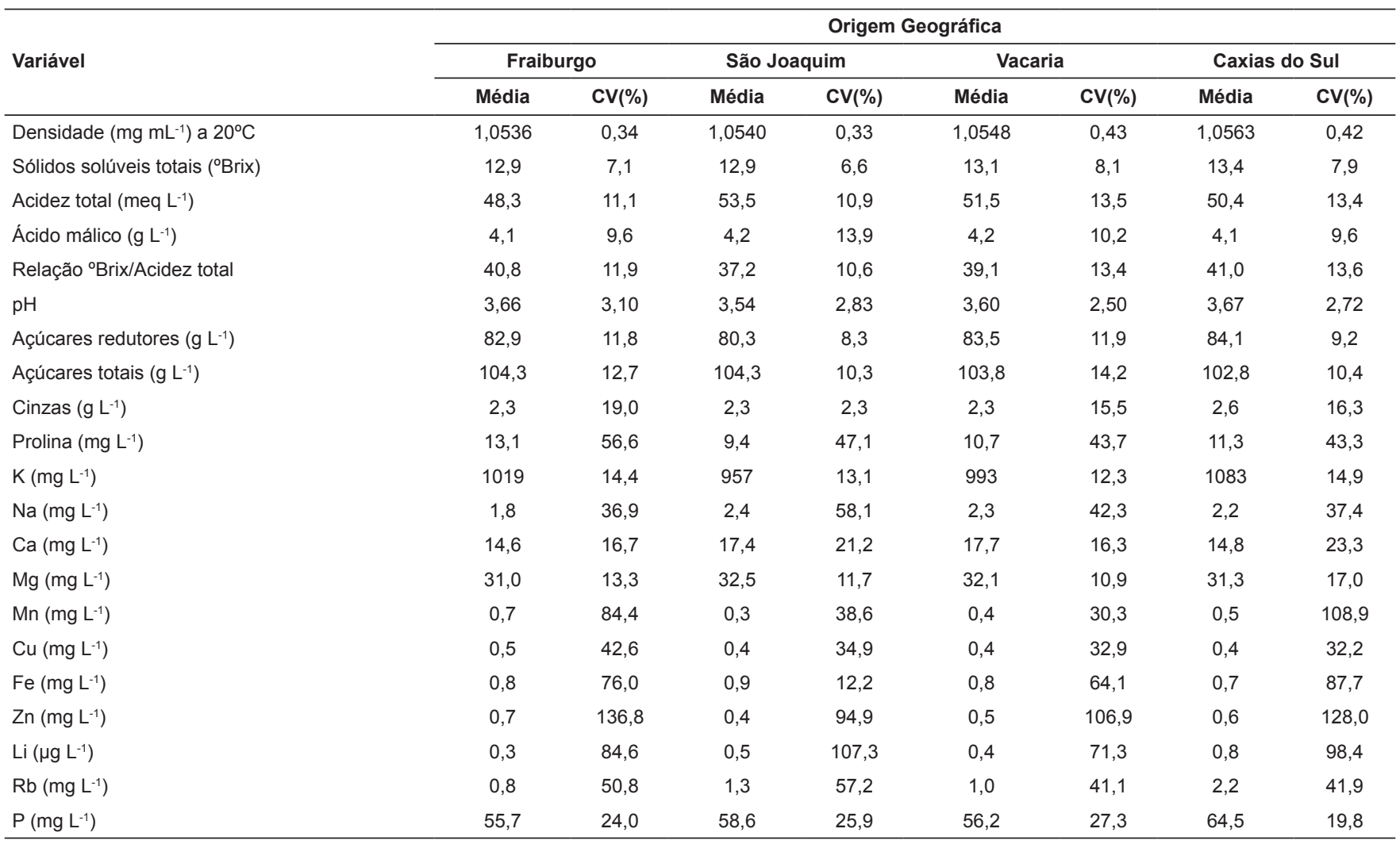


às cultivares, a Golden Delicious se caracterizou por ter acidez total e teor de ácido málico mais elevados e, conseqüentemente, valor de $\mathrm{pH}$ mais baixo. A cultivar Fuji diferenciou-se por apresentar sólidos solúveis totais ( ${ }^{\circ} \mathrm{Brix}$ ) e açúcares redutores mais elevados em relação aos sucos das outras duas cultivares. A Gala teve teores mais elevados de prolina e de Ca e mais baixos de açúcares redutores e de açúcares totais.

A ACP mostra que os eixos 1, 2 e 3 explicam $39,6 \%$, $31,2 \%$ e $10,5 \%$, respectivamente, ou seja, $81,3 \%$ da variação total. A Figura 1 corresponde à representação gráfica da projeção dos sucos das maçãs Gala, Golden Delicious e Fuji no plano formado pelos eixos 1 e 2 .

O eixo 1 permitiu separar os sucos das maçãs em função da cultivar e da origem geográfica formando três grupos distintos, sendo um para cada cultivar. No caso das maçãs Fuji e Golden Delicious, os sucos de Vacaria - RS e de São Joaquim - SC apresentaram maiores semelhanças em relação à composição química, sendo que os de Caxias do Sul - RS e Fraiburgo - SC se diferenciaram mais possivelmente em decorrência da localização geográfica e das condições edafoclimáticas. No entanto, considerando a cultivar, o eixo 2 apresentou maior efeito discriminante, pois permitiu separar os sucos das maçãs Gala e Golden Delicious localizadas nos dois extremos desse eixo (Figura 1).

A representação gráfica das variáveis no plano formado pelos eixos 1 e 2 é indicada na Figura 2 .

Entre as variáveis que participaram da formação do eixo 1, destacam-se os sólidos solúveis totais ( ${ }^{\circ} \mathrm{Brix}$ ), a densidade

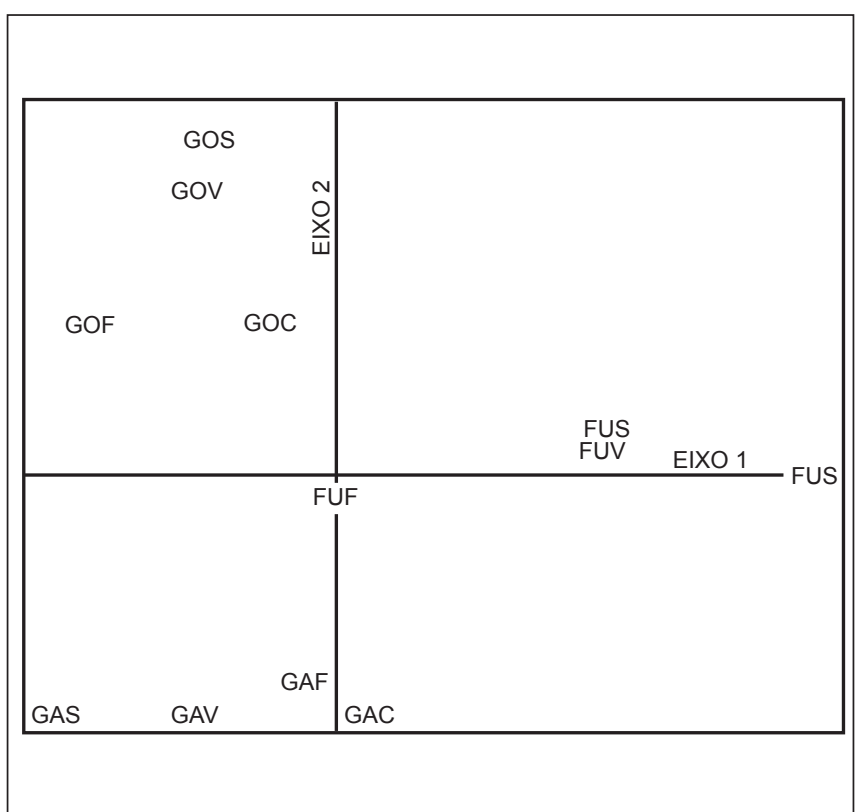

FIGURA 1 - Projeção dos sucos de maçã sobre o plano formado pelos eixos 1 e 2

FVF - Fuji de Fraiburgo; FUS - Fuji de São Joaquim; FUV - Fuji de Vacaria; FUC - Fuji de Caxias do Sul; GOF - Golden Delicious de Fraiburgo; GOS - Golden Delicious de São Joaquim; GOV - Golden Delicious de Vacaria; GOC - Golden Delicious de Caxias do Sul; GAF; Gala de Fraiburgo; GAS - Gala de São Joaquim; GAV - Gala de Vacaria ; GAC - Gala de Caxias do Sul
(DEN), os açúcares redutores (AR), a relação ${ }^{\circ}$ Brix/acidez total (B/A), a acidez total (ACT), o ácido málico (ACM) e os minerais: $\mathrm{Mg}, \mathrm{Cu}, \mathrm{Zn}, \mathrm{Rb}$ e $\mathrm{P}$, todos com correlação acima da 0,6000 (Tabela 3).

Os sólidos solúveis totais ( ${ }^{\circ}$ Brix) representam um conjunto de substâncias presentes no suco de maçã, com predominância dos açúcares, os quais estão diretamente relacionados com a densidade (DEN). Participam diretamente também da relação ${ }^{\circ} \mathrm{Brix} / \mathrm{acidez}$ total $(\mathrm{B} / \mathrm{A})$, que indica o equilíbrio entre os gostos doce e ácido, aspecto importante na qualidade do suco de maçã. No presente estudo, o ${ }^{\circ}$ Brix teve participação elevada na diferenciação do suco da maçã Fuji, que se distinguiu por apresentar teor mais elevado em comparação com as outras duas cultivares. Além do aspecto genético, outros fatores interferem na produção de açúcar no suco da maçã, especialmente as variáveis que participam da fotossíntese como a intensidade de calor, a radiação solar e a umidade do solo. Logo, regiões de clima quente no período de maturação da maçã favorecem a produção de açúcar e conseqüentemente de sólidos solúveis totais ( $\left.{ }^{\circ} \mathrm{Brix}\right)$. Nesse sentido, destacou-se o mosto da maçã Fuji proveniente de Caxias do Sul - RS com ${ }^{\circ}$ Brix mais elevado, provavelmente em função dos fatores que favorecem a atividade fotossintética.

A acidez total (ACT) e o ácido málico (ACM) também participaram na formação do eixo 1 e possibilitaram a diferenciação do suco da maçã Golden Delicious, com acidez total (ACT) mais elevada e do suco da maçã Gala, com acidez mais baixa. O teor de acidez total (ACT) diminuiu no período de amadurecimento; no entanto, algumas cultivares, como a Golden Delicious, alcançam um nível de maturação

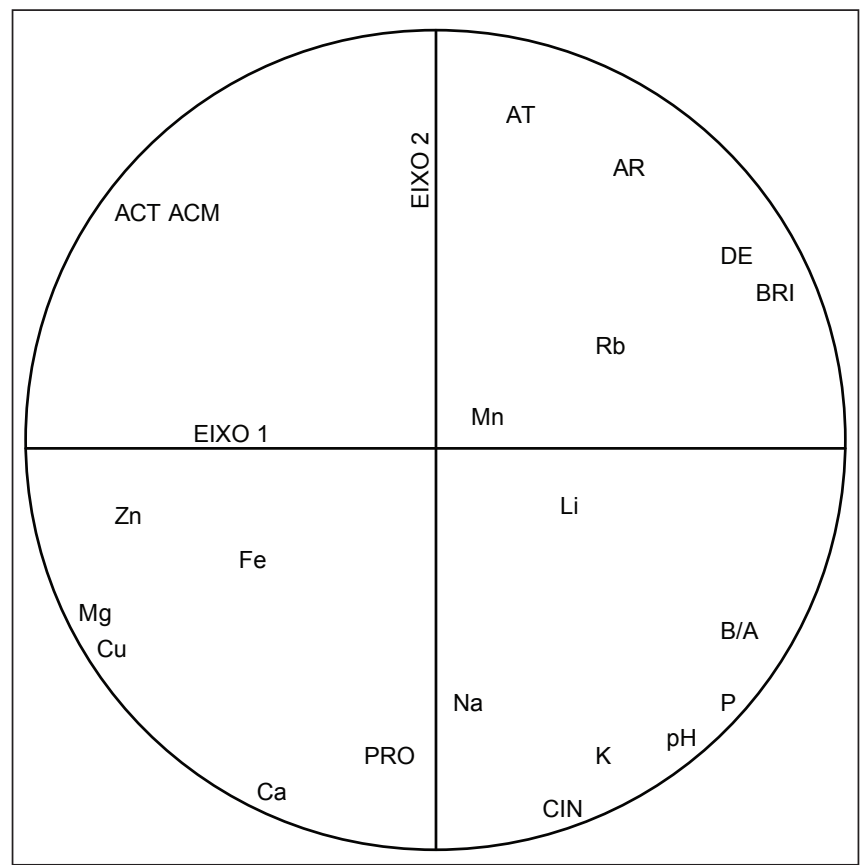

FIGURA 2 - Círculo das correlações do plano formado pelos eixos 1 e 2

DEN - Densidade; ${ }^{\circ}$ Brix - Sólidos solúveis totais ( $\left.{ }^{\circ} \mathrm{Brix}\right)$; ACT - Acidez total; ACM - Ácido málico; B/A - Relação ${ }^{\circ}$ Brix/Acidez total; $\mathrm{pH} ; \mathrm{AR}$ - Açúcares redutores; AT - Açúcares totais; CIN - Cinzas; PRO-Prolina; K; Na; Ca; Mg; Mn; Cu; Fe; Zn; Li, Rb e P 
e são colhidas com teor de acidez total (ACT) mais elevado, devido especialmente ao teor de ácido málico (ACM).

Entre os elementos minerais, o Mg é um dos componentes da clorofila e da pectina. Esse cátion é absorvido pelo sistema radicular e sua presença está relacionada com a quantidade disponível no solo e com a seletividade da planta. $\mathrm{O}$ excesso de $\mathrm{K}$ e a falta de umidade $\mathrm{e}$ de aeração do solo dificultam a absorção do Mg. Nesse sentido, a concentração de Mg no suco da maçã contribuiu para diferenciar a cultivar Fuji, com teor mais baixo, da Gala e da Golden Delicious, com teores mais elevados. No entanto, mesmo considerando a concentração mais elevada de $\mathrm{Mg}$, ela é baixa quando comparada com os teores de sucos de maçã de outras regiões produtoras $[12,13,24]$. O Zn e o Cu são dois micronutrientes extraídos do solo em pequena quantidade. Além disso, alguns produtos fitossanitários utilizados para controle de doenças podem interferir nos teores desses minerais no suco da maçã. A disponibilidade de $\mathrm{Zn}$ no solo varia com o tipo, o teor de matéria orgânica e com a acidez. Por outro lado, o aumento do $\mathrm{pH}$ reduz a disponibilidade desse mineral no solo e a adubação fosfatada excessiva pode afetar sua absorção. De outra parte, os teores de $\mathrm{Zn}$ podem ser excessivos quando aplicados via foliar. Em relação ao $\mathrm{Cu}$, o aumento do $\mathrm{pH}$ do solo, a retenção da matéria orgânica e a ocorrência de períodos de seca diminuem sua disponibilidade no solo. Esses dois micronutrientes foram detectados em concentrações mais baixas no suco da cultivar Fuji. Mesmo assim, os teores de $\mathrm{Cu}$ e $\mathrm{Zn}$ encontrados nos sucos de maçã estudados sempre foram baixos em relação aos elaborados em outras regiões produtoras [13, 24].

$\mathrm{O} \mathrm{Rb}$ é um mineral pouco difundido na natureza, mas é estudado devido a sua contribuição para a identificação da origem geográfica [18]. No presente estudo, o teor de Rb do suco de maçã Fuji de Caxias do Sul - RS contribuiu para diferenciá-lo dos demais. Os teores de $\mathrm{Rb}$ detectados nos sucos de maçã analisados sempre foram inferiores a 3,5 mg L-1, o que corresponde ao teor médio dos sucos de maçã de outras regiões produtoras [13]. O P é um macronutriente absorvido do solo e sua concentração no suco de maçã está relacionada com o grau de exigência e a capacidade de absorção do sistema radicular das cultivares. O P encontrado no suco de maçã contribuiu para a diferenciação do suco da Golden Delicious, com teor mais baixo, das demais, com concentrações mais elevadas. O teor de P no suco de maçã variou de 44,2 mg L-1 na Golden Delicious a 69,8 mg L-1, no da Fuji.

O eixo 2 teve efeito discriminante importante para separar os sucos das maçãs Golden Delicious daqueles da Gala. Dentre as variáveis que participaram da formação desse eixo destacam-se os açúcares totais (AT), as cinzas (CIN), a prolina (PRO), o pH e os minerais Ca e $\mathrm{K}$.

Os açúcares totais (AT) são constituídos pela soma dos açúcares redutores (AR) e dos não redutores, representados principalmente pela sacarose. O teor mais elevado de açúcares totais (AT) detectado no suco da maçã Golden Delicious

TABELA 3 - Correlação entre as variáveis e os três principais eixos

\begin{tabular}{|c|c|c|c|}
\hline \multirow{2}{*}{ Variável } & \multicolumn{3}{|c|}{ Eixo } \\
\hline & 1 & 2 & 3 \\
\hline Densidade $\left(\mathrm{mg} \mathrm{mL}^{-1}\right)$ a $20^{\circ} \mathrm{C}$ & $0,8960^{*}$ & 0,3670 & $-0,1361$ \\
\hline Acidez total $\left(m e q \mathrm{~L}^{-1}\right)$ & $-0,7076^{*}$ & 0,6121 & $-0,2094$ \\
\hline Ácido málico $\left(\mathrm{g} \mathrm{L}^{-1}\right)$ & $-0,6271^{*}$ & 0,6058 & $-0,2392$ \\
\hline Açúcares redutores $\left(\mathrm{g} \mathrm{L}^{-1}\right)$ & $0,6269^{*}$ & $0,7499^{*}$ & 0,1230 \\
\hline Açúcares totais $\left(\mathrm{g} \mathrm{L}^{-1}\right)$ & 0,1952 & $0,9074^{*}$ & 0,1185 \\
\hline Cinzas $\left(\mathrm{g} \mathrm{L}^{-1}\right)$ & 0,2905 & $-0,8875^{*}$ & $-0,1231$ \\
\hline Prolina (mg L-1) & $-0,1998$ & $-0,7634^{*}$ & 0,5308 \\
\hline $\mathrm{Mn}\left(\mathrm{mg} \mathrm{L}^{-1}\right)$ & 0,1295 & $-0,1544$ & 0,5920 \\
\hline $\mathrm{Cu}\left(\mathrm{mg} \mathrm{L}^{-1}\right)$ & $-0,8629^{*}$ & $-0,2980$ & $-0,1925$ \\
\hline $\mathrm{Fe}\left(\mathrm{mg} \mathrm{L}^{-1}\right)$ & $-0,3306$ & $-0,2772$ & $-0,7286^{*}$ \\
\hline $\mathrm{Zn}\left(\mathrm{mg} \mathrm{L}^{-1}\right)$ & $-0,7911^{*}$ & $-0,2260$ & 0,1573 \\
\hline $\operatorname{Li}\left(\mu \mathrm{g} \mathrm{L}^{-1}\right)$ & 0,3191 & $-0,0370$ & 0,2916 \\
\hline $\mathrm{Rb}\left(\mathrm{mg} \mathrm{L}^{-1}\right)$ & $0,6951^{*}$ & 0,2265 & $-0,3169$ \\
\hline$P\left(m g L^{-1}\right)$ & $0,7215^{*}$ & $-0,6272$ & $-0,1945$ \\
\hline
\end{tabular}

* Correlações consideradas importantes 
deveu-se provavelmente a uma característica varietal. No entanto, a colheita antecipada da maçã determina maior teor de amido e de acidez total (ACT) e menor de açúcar redutor (AR). As cinzas (CIN) representam o conjunto dos minerais presentes nos sucos de maçã. Os teores estão relacionados com a cultivar, o grau de maturação, a origem geográfica e o tipo e a fertilidade do solo. O teor de cinzas (CIN) contribuiu para a diferenciação dos sucos das maçãs Golden Delicious, com concentração mais baixa, e Gala, cujos sucos apresentaram teores mais elevados. A prolina (PRO) é um aminoácido utilizado para diferenciar o suco de maçã dos de outras frutas [13]. O teor de prolina (PRO) do suco de maçã é baixo, geralmente menor de $15 \mathrm{mg} \mathrm{L}-1$. A legislação argentina estabelece em 17 mg L-1 o teor máximo de prolina (PRO) do suco de maçã. No presente estudo, constatou-se pouca variabilidade na concentração de prolina (PRO), sendo a Gala a que teve teor mais elevado.

O Ca está presente no suco de maçã em concentração variável de 30 a 120 mg L-1 [13, 24]. Os teores detectados sempre foram inferiores a $30 \mathrm{mg} \mathrm{L}-1$, portanto considerados baixos. A concentração desse mineral pode ser conseqüência da forma de extração do suco, na qual foi utilizada pressão reduzida, mas também das características do solo onde é cultivada a macieira. O efeito discriminante do $\mathrm{Ca}$ para diferenciar os sucos das maçãs ocorreu devido a sua presença em concentração mais elevada na Gala.

\section{4 - CONCLUSÕES}

A ACP permitiu caracterizar e diferenciar os sucos das maçãs Gala, Golden Delicious e Fuji cultivadas no Sul do Brasil. As variáveis que apresentaram maior efeito foram os sólidos solúveis totais ( $\left.{ }^{\circ} \mathrm{Brix}\right)$, a densidade (DEN), os açúcares redutores (AR), a relação ${ }^{\circ} \mathrm{Brix} / \mathrm{acidez}$ total $(\mathrm{B} / \mathrm{A})$, a acidez total (ACT), o ácido málico (ACM) e os minerais $\mathrm{Mg}, \mathrm{Cu}, \mathrm{Zn}, \mathrm{Rb}, \mathrm{P}$ e K.

O suco de maçã Fuji caracterizou-se pelo maior teor de sólidos solúveis totais ( $\left.{ }^{\circ} \mathrm{Brix}\right) \mathrm{e}$, conseqüentemente, maior valor da densidade (DEN), relação ${ }^{\circ}$ Brix/acidez total (B/A) e $\mathrm{Rb}$; o da Gala, pelos teores mais elevados de cinzas (CIN), prolina (PRO) e Ca; e o da Golden Delicious, por valores mais elevados de acidez total (ACT) e de ácido málico (ACM), distinguindo-se, portanto, pela acidez.

Quanto à origem geográfica, os sucos de maçã de São Joaquim - SC e de Vacaria - RS mostraram maiores semelhanças, principalmente nas cultivares Fuji e Golden Delicious; os de Caxias do Sul se diferenciaram pelos teores mais elevados de açúcares redutores (AR), de Rb, de sólidos solúveis totais ( ${ }^{\circ} \mathrm{Brix}$ ) e de açúcares redutores (AR).

\section{5 - REFERÊNCIAS BIBLIOGRÁFICAS}

[1] ARTHEY, D.; ASHURST, P.R. Procesado de frutas. Zaragoza: Acribia, 1997.

[2] AUGUSTE, M.H. Application de la Cromatographie en Phase Liquide à Haute Pression à l'Analyse des Moûts et des Vins. Premiers Résultats. Talence, 1979, 135 p. Tese (Doutorado em Enologia
- Ampelologia), Institut d’Oenologie, Université de Bordeaux II.

[3] CUNHA, S.C.; FERNANDES, J.O.; FERREIRA, I.M. HPLC/UV determination of organic acids in fruit juices and nectars. European Food Research and Technology. v. 214, n. 1, p. 67-71, 2002.

[4] ELKINS, E.R.; HENSER, J.R. Detection of adulteration in selected fruit juices. In: NAGY, S.; ATTAWAY, J.A.; RHODES, M.E. (Ed.). Adulteration of Fruit Juice Beverages. New York: Marcel Dekker, 1988. p. 317-341.

[5] EPAGRI. A Cultura da Macieira. Florianópolis, 2002.

[6] FOUCART, T. Analyse Factorielle. Programation sur Micro-ordinateurs. Paris: Masson, 1982.

[7] GIANESSI, P.; MATTA, M. Trattato di Scienza e Tecnica Enologica. Brescia: AEB, 1987.

[8] GLISZCZYNSKA-SWIGLO, A.; TYRAKOWSKA, B. Quality of commercial apple juices evaluated on the basis of the polyphenol content and the TEAC antioxidant activity. Journal of Food Science, v. 68 , n. 5, p. 1844-1849, 2003.

[9] JANZANTTI, N.S.; FRANCO, M.R.B.; WOSIACKI, G. Efeito do processamento na composição de voláteis de suco clarificado de maçã Fuji. Ciência e Tecnologia de Alimentos, v. 23, n. 3, p. 523-528, 2003.

[10] KARADENIZ, F.; EKSI, A. Sugar composition of apple juices. European Food Research and Technology, v. 215, n. 2, p. 145-148, 2002.

[11] LEE, S.H.; HROLSTAD, R.E. Detection of adulteration in apple juices. In: NAGY, S.; ATTAWAY, J.A.; RHODES, M.E. (Ed.). Adulteration of Fruit Beverages. New York: Marcel Dekker, 1988. p. 343-376.

[12] MATTICK, L.R. An evaluation of the methodology for determining the authenticity of apple juice and concentrate. In: NAGY, S.; ATTAWAY, J.A.; RHODES, M.E. (Ed.). Adulteration of Fruit Juice Beverages. New York: Marcel Dekker, 1988. p. 175-193.

[13] MATTICK, L.R. Chemical composition of apple juice. In: DOWNING, D.L. (Ed.). Apple Juice Workshop. New York: Cornell Cooperative Extension, Institute of Food Science, Cornell University, 1984. p. 2-4.

[14] MOTA, F.S.; ALVES, E.G.P. Regiões edafoclimáticas preferenciais para a macieira no Rio Grande do Sul. HortiSul, v. 1, n. 3, p. 18-24, 1990.

[15] Normas Analíticas do Instituto Adolfo Lutz. $3^{a}$ ed. São Paulo: Instituto Adolfo Lutz, 1985.

[16] PERKIN-ELMER. Analytical Methods for Atomic Absorption Spectrophotometry. Singapura: PerkinElmer, 2000.

[17] PROTZEK, E.C.; FREITAS, R.J.S.; WASZCNSKYJ, N.; FONTOURA, P.S.G. Avaliação sensorial de suco de maçã produzido a partir de rejeitos de produção. Boletim do CEPPA, v. 17, n. 1, p. 59-70, 1999.

[18] RIZZON, L. A.; MIELE, A.; ROSIER, J.P. Discrimination of wines from the Mercosul countries according to their mineral composition. Journal International des Sciences de la Vigne et du Vin, v. 31, n. 1, p. 43-47, 1997.

[19] SCHIEBER, A.; KELLER, P.; CARLE, R. Determination of phenolic acids and flavonoids of apple and pear by high-performance liquid chromatography. Journal of Chromatography, v. 910, n. 2, p. 265-273, 2001. 
[20] Situação da Safra 2000/01 e Previsão da Safra 2001/02 de Frutas de Clima Temperado. Jornal da Fruta, v. 10, n. 116, p. 6, 2002.

[21] SOARES, L.M.; SHISHIDO, K.; MORAES, A.M.M.; MOREIRA, V.A. Composição mineral de sucos concentrados de frutas brasileiras. Ciência e Tecnologia de Alimentos, v. 24, n. 2, p. 202-206, 2004.

[22] USHIROZAWA, K. A Cultura da Maçã. Florianópolis: Empasc, 1978.

[23] VARNAN, A.H.; SUTHERLAND, J.P. Bebidas. Tecnología, Química y Microbiología. Zaragoza: Acribia, 1997.

[24] WALLRAUCH, S.; FAETHE, W. Germany: RSK values
- guidelines and tolerances for specified constituents in fruit juice. In: NAGY, S.; ATTAWAY, J.A.; RHODES, M.E. (Ed.). Adulteration of Fruit Juice Beverages. New York: Marcel Dekker, 1988. p. 405-470.

[25] WESTPHALEN, S.L.; MALUF, J.R.T. Zoneamento agroclimático da macieira no Rio Grande do Sul. In: Congresso brasileiro de fruticultura, 5., 1979, Pelotas, RS. Anais... Pelotas: Sociedade Brasileira de Fruticultura, 1979. p. 315-326.

[26] WOSIACKI, G.; PHOLMAN, B.C.; NOGUEIRA, A. Características de cultivares de maçã: avaliação físico-química e sensorial de quinze cultivares. Ciência e Tecnologia de Alimentos, v. 24, n. 3, p. 347-352, 2004. 